\title{
Experimental Investigation of Adsorption-Flocculation-Microfiltration Hybrid System in Wastewater Reuse
}

\author{
W.S. Guo ${ }^{\mathrm{a}}$, H. Chapman ${ }^{\mathrm{b}}$, S. Vigneswaran ${ }^{\mathrm{c} *}$ and H.H. Ngo ${ }^{\mathrm{d}}$ \\ ${ }^{a, b, c, d}$ Faculty of Engineering, University of technology, Sydney, \\ P.O. Box 123, Broadway, NSW 2007, Australia \\ ${ }^{a}$ tel: +61-2-95142745, fax:+61-2-95142633,E-mail:Wenshan.Guo@uts.edu.au \\ ${ }^{b}$ tel: +61-2-95142745, fax: +61-2-95142633, E-mail: Hugh.A.Chapman@uts.edu.au \\ ${ }^{c} *$ Correspondence author, tel: +61-2-9514-2641, fax: + 61-2-9514-2633, \\ E-mail: S.Vigneswaran@uts.edu.au \\ ${ }^{d}$ tel: +61-2-95141693,fax: +61-2-95142633,E-mail: h.ngo@uts.edu.au
}

Keywords: microfiltration, fouling, water treatment, powdered activated carbon, critical flux

\begin{abstract}
Membrane hybrid systems are becoming increasingly important as cost effective solutions in wastewater treatment and reuse. The effects of pretreatment namely floating medium flocculation (FMF) and powdered activated carbon (PAC) adsorption on organic and phosphorus removal was studied. The FMF was found to increase the phosphorus removal up to $97 \%$. This preflocculation improved the dissolved organic removal only marginally (from $20 \%$ to $40 \%$ ) whilst the pretreatment of adsorption increased the organic removal to more than $98 \%$. The decline in filtration (permeate) flux of microfiltration was reduced by the incorporation of these pretreatment methods. Detailed studies on the effect of PAC dose indicated that a PAC dose of $1 \mathrm{~g} / \mathrm{L}$ was the optimum in terms of organic removal and filtration flux. PAC doses in excess of $1 \mathrm{~g} / \mathrm{L}$ contributed to a significant decrease in filtration flux.

The critical flux was experimentally evaluated for crossflow microfiltration (CFMF) with and without the pretreatment. The pretreatment of adsorption led to six times higher critical flux than that without any pretreatment. The preflocculation
\end{abstract}


alone did not significantly increase the critical flux. There was only a $33 \%$ increase with preflocculation. However, the preflocculation combined with PAC adsorption resulted in nine times higher critical flux.

The results showed that a pretreatment of flocculation and adsorption led to almost complete phosphorus and organic removal while reducing the membrane clogging.

\section{Introduction}

Crossflow microfiltration (CFMF) is a pressure driven process with a microporous membrane as a separating medium. This process is generally used to filter suspended solids of colloidal or fine particles with a size range of between 0.02 and $10 \mu \mathrm{m}$. The majority of the pollutants found in water and wastewater (other than the dissolved organics) fall within this size range, which therefore makes microfiltration a very useful unit operation in water treatment and wastewater treatment for reuse. One of the major drawbacks hindering widespread application of membrane processes in water and wastewater treatment is the gradual reduction in the filtration (permeate) flux below the theoretical capacity of the membranes due to membrane clogging. This membrane clogging is generally caused by the deposition of particles on and within the membrane surface. The formation of a solid "Cake" occurs over the filtration time, when suspended particles in the wastewater build-up on the membrane surface. Under the conditions of constant transmembrane pressure (TMP) and crossflow velocity, the filtration flux in microfiltration declines to a steady state value which can be as much as two orders of magnitude lower than the initial filtration flux. Research into crossflow microfiltration has therefore been focused on overcoming this decline in filtration flux and membrane clogging. To achieve this goal, researches have experimented with membrane modifications, the feed water, and the fluid dynamics in 
the membrane modules. This fluid dynamics approach focuses on the design of membrane modules and optimization of operating conditions. By operating the microfiltration below critical flux, one can avoid or minimize the membrane fouling. Another more effective way of improving the filtration performance of the membrane is through the modification of the feed water. Preflocculation (or inline flocculation) of the feed water with flocculants has been shown to modify the way that the suspended solids deposit on the membrane, and therefore affect the membranes performance. The preflocculation not only leads to superior removal of particulates, but also reduces the decline in filtration flux [1]. Flocculation as pretreatment can remove most of the organic colloids present in the biologically treated sewage effluent. Adin et al. [2] have shown the superiority of ferric chloride $\left(\mathrm{FeCl}_{3}\right)$ over aluminum sulphate (alum) in flocculating the organic colloids present in the activated sludge effluent. Al-Malack et al. [3] have studied the effect of alum, polyaluminium silicate sulfate (PASS) and lime as flocculants on the performance of cross-flow microfiltration of domestic wastewater. Chapman et al. [4] showed the importance of $\mathrm{FeCl}_{3}$ flocculation on the performance of crossflow microfiltration of biologically treated effluent. Flocculation as pretreatment can only help in the removal of organic colloids, but cannot remove the dissolved organics.

A pretreatment of adsorption, on the other hand, can remove the dissolved organics. Vigneswaran et al. [5] showed that the direct addition of powdered activated carbon (PAC) (as adsorbent) into the submerged membrane reactor could lead to more than $80 \%$ dissolved organics removal. A biologically treated wastewater was used in their study. A dose of $1 \mathrm{~g} / \mathrm{L}$ of powdered activated carbon was added to the biologically treated wastewater once every 20-30 days of operation. This kept the organic removal efficiency constant without the need for chemically cleaning the membrane for a long 
time. This minimized also the biofouling of the membranes. Abdessemed et al. [6] showed experimentally that the flocculation-adsorption process could be able to remove $86 \%$ of chemical oxygen demand from domestic wastewater. In their study, they used $\mathrm{FeCl}_{3}$ at a concentration of $40 \mathrm{mg} / \mathrm{L}$ and $\mathrm{PAC}$ at a dose of $20 \mathrm{mg} / \mathrm{L}$. Such chemical coupling with membrane filtration in wastewater treatment systems are becoming more important, as the focus on water reuse increases throughout the world.

This paper discusses the performance of CFMF (hollow fiber configuration) in removing the organics from biologically treated wastewater effluent with and without chemical coupling of flocculation and adsorption. The flocculation was provided through a FMF and adsorption through PAC addition. The characteristics of PAC used in the experiments are shown in Table 1. The reduction in the decline in filtration flux with time through the adoption of these pretreatment was also investigated. The effect of pretreatment on the critical flux was experimentally tested.

Table 1 Characteristics of powdered activated carbon (PAC) used

In this study, a biologically treated wastewater (sewage) effluent was used. The wastewater characteristics are shown in Table 2. Figure 1 shows the change in turbidity, TOC and suspended solids over the experimental period.

Table 2 Specific characteristics of wastewater used over the experimental period Figure 1. Influent variation over time (Turbidity (NTU); Orthophosphate $\left(\mathrm{PO}_{4}{ }^{-3} \mathrm{mg} / \mathrm{L}\right)$; TOC (ppm C); Suspended Solids (mg/ L).

\section{Critical flux with the Hybrid System}

As a first step, the importance of pretreatment of flocculation and adsorption in increasing the critical flux was investigated using a laboratory-scale flat-plate membrane unit. Here, the critical flux is defined as the maximum flux that does not lead to any TMP increase with time. 
Under the conditions of constant TMP and crossflow velocity, the flux in CFMF declines to a steady-state value which can be as much as two orders of magnitude lower than the initial or clean water value [7]. Howell [8] and Field et al. [9] found significant advantage in CFMF operation (no fouling effect) when it was operated in sub-critical flux condition. Based on their experimental result, they stated that there exists a critical flux below which a decline of flux with time does not occur; but above this flux, the fouling is observed. The value of critical flux depends on the hydrodynamics and also on the particle size and their surface and chemical characteristics [10]. This hypothesis of critical flux suggests that when CFMF is operated below a certain filtration flux (critical flux), the fouling of the membrane can be prevented.

\subsection{Critical flux experimental setup}

The schematic diagram of the flat-plate microfiltration set-up used in the critical flux experiments is shown in Figure 1. In this study, the flat-plate microfiltration was used. The total membrane area was $3.24 \times 10^{-3} \mathrm{~m}^{2}$. The solution was circulated along the surface of the flat-plate membrane in the module. The membranes used are PVDF (modified polyvinylidene difluoride) Minitan-S Microporous Sheets (with pore size of $0.65 \mu \mathrm{m})$. In each experiment, new membrane was used to obtain reproducible results. The biologically treated wastewater was delivered from a stock tank to the CFMF cell. The reject water and filtrate were returned to the feed tank. The pressure of membrane was controlled by two valves and the transmembrane pressure change was monitored by using a pressure transducer at three points P1, P2 and Pf respectively. During the experiment, the filtration flux at each step was kept constant for at least 40 minutes by 
the use of suction pump, the speed of which can be changed. The TMP was calculated using the following equation:

$$
\mathrm{TMP}=(\mathrm{P} 1+\mathrm{P} 2) / 2-\mathrm{Pf}
$$

Figure 2 The schematic diagram of the CFMF experimental set-up

\subsection{Effect of flocculation on critical flux}

Figure 3 shows the TMP value for different filtration flux values. The biologically treated wastewater without and with preflocculation was used as feed water. The critical flux was around $150 \mathrm{~L} / \mathrm{m}^{2} \mathrm{~h}$ for the wastewater with no preflocculation. It increased to $200 \mathrm{~L} / \mathrm{m}^{2} \mathrm{~h}$ with the flocculated wastewater. The results indicated that the pretreatment of flocculation did not affect the critical flux significantly. This may be due to the fact that flocculation removed only the organic colloids from the biologically treated effluent.

Figure3 Effect of flocculation on critical flux

$\left(\mathrm{FeCl}_{3}=50 \mathrm{mg} / \mathrm{L} ;\right.$ crossflow velocity $=0.15 \mathrm{~m} / \mathrm{s} ;$ membrane pore size $\left.=0.65 \mu \mathrm{m}\right)$

(Note: The ranges of filtration flux values for flocculated and non-flocculated wastewater are different)

\subsection{Effect of adsorption on critical flux}

The effect of adsorption on critical flux was investigated. Both preflocculated and non-preflocculated wastewaters were used. The results showed that the filtration flux improved dramatically when powdered activated carbon at a dose of $2 \mathrm{~g} / \mathrm{L}$ was added to the non-flocculated wastewater. The critical flux was in the range around 900 $\mathrm{L} / \mathrm{m}^{2} \mathrm{~h}$ (Fig. 4). On the other hand, when both flocculation and adsorption were used as pretreatment, the increase in critical flux was still higher $\left(1400 \mathrm{~L} / \mathrm{m}^{2} \mathrm{~h}\right)$. 
Figure 4 Effect of (i) adsorption and (ii) flocculation and adsorption as pretreatment on critical flux $\left(\mathrm{PAC}=2 \mathrm{~g} / \mathrm{L} ; \mathrm{FeCl}_{3}=50 \mathrm{mg} / \mathrm{L}\right.$; crossflow velocity $=0.15 \mathrm{~m} / \mathrm{s}$;

membrane pore size $=0.65 \mu \mathrm{m}$ )

(Note: The ranges of filtration flux values for adsorption and flocculation-adsorption pretreatment are different)

The summary of critical flux results are shown in Table 3 for comparison.

Table 3 The critical flux under different pretreatment conditions

\section{Microfiltration experiments with pretreatment}

\subsection{Experimental setup}

The importance of flocculation and adsorption as pretreatment to CFMF was studied using a hollow fiber module of CFMF with a total membrane area of $1 \mathrm{~m}^{2}$ (US Filter Memcor membrane module).

\subsubsection{Crossflow microfiltration (CFMF)}

A hollow fiber CFMF was used in the on-site experiments. The membrane material is polypropylene with pore size of $0.2 \mu \mathrm{m}$. The microfiltration unit is equipped with an automatic programmatic air backwash system, in which compressed air is used to dislodge waste particles from the surface of the membrane as part of the backwash sequence. In the present experiments air back wash was performed every 36 minutes for duration of 2 minutes. This is followed by a series of high power water blasts to wash the particles out of the membrane system.

\subsubsection{Flocculation unit}

In order to study the effect of flocculation as pretreatment, a floating medium flocculator (FMF) was used prior to the CFMF membrane unit. FMF has been found 
to a convenient static flocculator, which can provide a uniform velocity gradient during the passage of wastewater through the filter bed [11]. In the FMF, the filter column was packed with polystyrene beads (diameter of $1.9 \mathrm{~mm}$, density of $50 \mathrm{~kg} / \mathrm{m}^{3}$, and porosity of approximately 0.36) (Fig. 5). The low density beads were used to economize the energy requirement for backwash. In these experiments, ferric chloride $\left(\mathrm{FeCl}_{3}\right)$ was used as a flocculant. A periodic backwash (1 min every 45 or 60 minutes) was conducted to clean the floating medium. The backwash flow rate was $30 \mathrm{~m} / \mathrm{h}$. This FMF unit was operated at a high filtration velocity of $30 \mathrm{~m} / \mathrm{h}$ and a high dose of $\mathrm{FeCl}_{3}(50 \mathrm{mg} / \mathrm{L})$ to achieve the phosphorus precipitation in addition to the flocculation of suspended solids. The effluent from the flocculator was used as feed water to the microfiltration unit.

\subsubsection{Adsorption-flocculation-microfiltration}

Although the FMF removes organic colloids and phosphorus, it cannot remove the majority of dissolved organic matter present in the biologically treated wastewater. To achieve the dissolved organic removal, adsorption with powdered activated carbon (PAC) is necessary. The schematic of the pilot-scale experimental set-up, which incorporates adsorption-flocculation-microfiltration, is shown in Figure 5. The setup consisted of a saturated flow FMF as the pretreatment followed by a mixing tank, in which, PAC of known concentration was added and mixed well with pre-flocculated wastewater before sending the effluent through the CFMF unit. The temperature varied from $25-30^{\circ} \mathrm{C}$ during the hybrid system experiments.

Figure 5 Schematic of flocculation-adsorption-microfiltration hybrid system 


\subsection{Results and discussion}

\subsubsection{Filtrate Quality}

The performance of the pretreatments was evaluated on their ability to improve the removal efficiency by the microfiltration. The performance is shown with respect to total organic carbon (TOC, mg/L), orthophosphate $\left(\mathrm{PO}_{4}{ }^{-3} \mathrm{mg} / \mathrm{L}\right)$ and turbidity (NTU). The ability of the pretreatment to improve the filtration flux was also examined. Table 4 compares the effluent quality with the pretreatments, as well as the effluent quality of the membrane without pretreatment.

Table 4 Effluent quality with different pretreatment.

$\left(\mathrm{FMF}\right.$ velocity $=40 \mathrm{~m} / \mathrm{h} ; \mathrm{FeCl}_{3}=50 \mathrm{mg} / \mathrm{L} ;$ PAC dose $=1 \mathrm{~g} / \mathrm{L} ;$ PAC mixing time $1-2$ minutes; Influent TOC Average $=2.75 \mathrm{mg} / \mathrm{L}$; duration $=2$ hours $)$

The membrane has the ability to remove the most of organic colloids without any pretreatment (Table 4). The ability of membrane in reducing the phosphorus and TOC on the other hand was limited without any pretreatment (e.g. removal of less than $5 \%$ of orthophosphate and $20 \%$ of TOC). When a pretreatment of flocculation (floating medium flocculator) was incorporated, the removal of both TOC and Orthophosphate was increased to $33 \%$ and $94 \%$. With this pretreatment, the decline in filtration flux with time was also lower $\left(277-265 \mathrm{~L} / \mathrm{m}^{2} . \mathrm{h}\right.$ with preflocculation instead of 277-245 $\mathrm{L} / \mathrm{m}^{2} . \mathrm{h}$ without preflocculation). The pretreatment of flocculation and adsorption presented an excellent TOC removal efficiency, which was more than $99.5 \%$.

\subsubsection{Effect of FMF as pretreatment on the CFMF}

The performance of FMF was studied at high rate $(30 \mathrm{~m} / \mathrm{h})$. Previous studies [4] showed the need for periodic backwash of flocculation column to maintain a consistent effluent quality and minimum headloss development. The backwash 
duration of 1 min every 45 minutes used in this study corresponds to less than $1.5 \%$ of daily water production which is less than the amount necessary for filter backwash in water treatment. The flocculator backwash frequency and duration were maintained at 45 min and 1 min respectively. As can be seen in Figure 6, the backwash frequency of 45 min led to uniform phosphorus and organic removal (Fig. 6(a) and Fig. 6(b)) with minimal headloss development (Fig. 6(c)). The headloss development rose up to 42 $\mathrm{kPa}$ (from the initial value of $20 \mathrm{kPa}$ ) in 45 minutes and dropped back to $20 \mathrm{kPa}$ soon after the backwash.

Figure 6 The floating medium flocculator performance (filter velocity $=30 \mathrm{~m} / \mathrm{h}$; polystyrene medium diameter $=1.9 \mathrm{~mm}$; filter depth $=0.8 \mathrm{~m}$; density $=50 \mathrm{~kg} / \mathrm{m}^{2}$; flocculator backwash frequency $=45 \mathrm{~min}$; backwash duration $=1$ $\mathrm{min}$; influent TOC $=2.09 \mathrm{mg} / \mathrm{L}$; orthophosphate $=2.68 \mathrm{mg} / \mathrm{L}$ )

The performance of CFMF with and without FMF as pretreatment was then studied. When the FMF was used as a pre-treatment (at a velocity of $30 \mathrm{~m} / \mathrm{h}$ ) to CFMF process, a very high phosphorus removal was obtained (Fig. 7). This is due to the chemical precipitation of ferric phosphate and its subsequent removal by the FMF and CFMF. The removal efficiency was more than $97 \%$.

When CFMF was used alone without any pretreatment, the filtration flux dropped significantly. The filtration flux was found to decline from $210 \mathrm{~L} / \mathrm{m}^{2} . \mathrm{h}$ to $180 \mathrm{~L} / \mathrm{m}^{2} . \mathrm{h}$ in six hours when no pretreatment was employed (Fig. 8). The adoption of a pretreatment of flocculation using FMF slowed down the declining rate of the filtration flux. During the six-hour experiment, the filtration flux only decreased from $216 \mathrm{~L} / \mathrm{m}^{2}$.h to $205 \mathrm{~L} / \mathrm{m}^{2}$.h when flocculation was used as pretreatment. However, the preflocculation did not significantly improve the TOC removal (Fig. 7). The preflocculation only helped to remove the TOC from $20 \%$ to $40 \%$.

Figure 7 Removal efficiency comparisons with and without flocculation as pretreatment (Filtration flux: $220 \mathrm{~L} / \mathrm{m}^{2}$. h; membrane backwash frequency $=36 \mathrm{~min}$ 
(backwash duration $2 \mathrm{~min}$ ); FMF velocity $=30 \mathrm{~m} / \mathrm{h} ; \mathrm{FeCl}_{3}$ dose $=50 \mathrm{mg} / \mathrm{L}$; flocculator backwash frequency $=60 \mathrm{~min}$ (backwash duration $1 \mathrm{~min})$ )

Figure 8 Variation of filtration flux of CFMF with filtration time for different pretreatment (Filtration flux $=220 \mathrm{~L} / \mathrm{m}^{2} . \mathrm{h}$; membrane backwash frequency $=36 \mathrm{~min}$; filtration velocity $=30 \mathrm{~m} / \mathrm{h} ; \mathrm{PAC}=1 \mathrm{~g} / \mathrm{L} ; \mathrm{FeCl}_{3}=50 \mathrm{mg} / \mathrm{L}$; flocculator backwash frequency $=60 \mathrm{~min}$ )

\subsubsection{Effect of flocculation and adsorption as pretreatment}

The flocculation as a pretreatment did not assist in achieving high TOC removal. In order to achieve higher TOC removal from wastewater, the experiments were conducted with adsorption as pretreatment. Here, PAC was used as adsorbent at a dose of $1 \mathrm{~g} / \mathrm{L}$.

Firstly, adsorption-microfiltration experiments were conducted with different doses of PAC at a filtration flux of $200 \mathrm{~L} / \mathrm{m}^{2} . \mathrm{h}$. The TOC removal efficiency and filtration flux are shown in Figures 9 and 10. When PAC dose was increased from $0.1 \mathrm{~g} / \mathrm{L}$ to $1 \mathrm{~g} / \mathrm{L}$, TOC removal efficiency increased from $60 \%$ to $90 \%$ (Fig. 9). There was hardly any difference in the efficiency when the PAC dose was increased from 1 $\mathrm{g} / \mathrm{L}$ to $5 \mathrm{~g} / \mathrm{L}$. Further, the filtration flux dropped significantly at a higher dose of PAC of $5 \mathrm{~g} / \mathrm{L}$. (Fig. 10). The lower values of filtration flux were observed at 210 and 240 minutes of operation as these times coincided with the backwashing time of the CFMF. The optimum dose in this case was around $1 \mathrm{~g} / \mathrm{L}$ (taking into account the cost, filtration flux and TOC removal efficiency). A long-term study made on the submerged membrane-adsorption system indicated that PAC at a dose of $1 \mathrm{~g} / \mathrm{L}$ can successfully used for few months before any necessary replacement is necessary. Thus, the adsorption will not significantly increase the operational cost. Further, the 
biological activity on the PAC can be encouraged, by which the PAC life time is increased.

Finally, experiments were conducted with flocculation-adsorption-microfiltration hybrid system with an initial filtration flux of $220 \mathrm{~L} / \mathrm{m}^{2} . \mathrm{h}$. The overall TOC removal of the flocculation-adsorption-microfiltration system reached to $98.5 \%$ (Fig. 11). The decline in filtration flux of CFMF was minimal from $211 \mathrm{~L} / \mathrm{m}^{2} . \mathrm{h}$ to minimal 208 $\mathrm{L} / \mathrm{m}^{2}$.h (Fig. 8). The incorporation of adsorbent (PAC) removed the majority of dissolved organics which were not removed by flocculation. This contributed to the significant reduction in membrane fouling.

Fig 9 TOC removal efficiency of adsorption-microfiltration system (Influent TOC $=2.4-3 \mathrm{mg} / \mathrm{L}$; membrane backwash frequency $=36 \mathrm{~min}$ (backwash duration $=2 \mathrm{~min}$ ); PAC mixing speed: $125 \mathrm{rpm}$ )

Fig 10 Filtration flux of adsorption-microfiltration hybrid system. (Influent TOC $=2.4-3 \mathrm{mg} / \mathrm{L}$; membrane backwash frequency $=36 \mathrm{~min}$; backwash during $=2$ min; PAC mixing speed: $125 \mathrm{rpm}$ )

Figure 11 TOC removal at different stages of the flocculation-adsorptionmicrofiltration hybrid system (Filtration flux $=220 \mathrm{~L} / \mathrm{m}^{2} \cdot \mathrm{h}$; membrane backwash frequency $=36 \mathrm{~min}$ (backwash duration $=2 \mathrm{~min}$ ); FMF filtration velocity $=30 \mathrm{~m} / \mathrm{h}$; $\mathrm{PAC}=1 \mathrm{~g} / \mathrm{L} ; \mathrm{FeCl}_{3}=50 \mathrm{mg} / \mathrm{L}$; flocculator backwash frequency $=60 \mathrm{~min}$ (backwash duration $=1 \mathrm{~min})$ )

\section{Conclusions}

The TOC and phosphorus removal by CFMF alone was very poor (as low as only $5 \%$ of $\mathrm{PO}_{4}^{-3}$ and $20 \%$ of TOC removal). The flocculation as pretreatment to CFMF (FMF-CFMF hybrid system) was successful in removing phosphorus (more than 97\%). The preflocculation also helped to reduce the decline in the filtration flux, which is due to organic colloids removal by flocculation. However, the preflocculation did not contribute to TOC removal efficiency. It was only able to 
remove $40 \%$ of TOC. The FMF used in this study is a simple static flocculator with no moving parts. The energy required for backwashing of this flocculator is minimum. As such, this preflocculation unit does not significantly increase the capital and, in particular, the operational cost.

The incorporation of adsorption (using PAC) as a pretreatment following the flocculation resulted in a higher TOC removal (almost 100\% with the PAC dose of 1 $\mathrm{g} / \mathrm{L}$ ). The introduction of adsorption further reduced the decline in of filtration flux of CFMF (less than $4 \%$ of flux declining after 6 hours of filter run).

The critical flux experiments conducted with laboratory-scale flat plate CFMF unit showed that the adsorption as pretreatment can increase the critical flux as high as six times of that with CFMF alone. The flocculation as pretreatment did not significantly increase the critical flux (only by $33 \%$ ).

\section{Acknowledgement}

This research was funded by ARC Discovery Grant.

\section{References}

[1] Kwon, D.Y., Vigneswaran, S., Ngo, H.H., and Shin, H.S., An enhancement of critical flux in crossflow microfiltration with a pretreatment of floating medium flocculator/prefilter, Wat. Sci. Tech., 36(1997) 267-274.

[2] Adin, A., Soffer, Y. and Ben Aim, R., Effluent pretreatment by iron coagulation applying various dose-pH combinations for optimum particle separation, Wat. Sci. and Tech., 38 (6) (1998) 27-34.

[3] Al-Malack M.H. and Anderson G.K., Coagulation-crossflow microfiltration of domestic wastewater, J. of Mem. Sci., 121 (1996) 59-70. 
[4] Chapman, H., Vigneswaran, S., Ngo, H.H., Dyer, S. and Ben Aim, R., Preflocculation of secondary treated wastewater in enhancing the performance of microfiltration, Journal of Desalination, 146 (2002) 367-372.

[5] Vigneswaran, S., Chaudhary, D.S., Ngo, H.H., Shim, W.G. and Moon, H., Application of a PAC-Membrane Hybrid System for Removal of Organics from Secondary Sewage Effluent: Experiments and Modelling, Separation Science and Technology, 38 (10) (2003) 2183-2199.

[6] Abdessemed, D., Nezzal, G. and Ben Aim, R., Coagulation-adsorptionultrafiltration for wastewater treatment reuse, Journal of Desalination, 131(2000) $307-314$

[7] Lojkine, M.H., Field, R.W. and Howell, J.A., Crossflow filtration of cell suspensions: A review of models with emphasis on particle size effects, Trans I Chem E, 70 (1992) Part C: 149.

[8] Howell, J.A., Sub-critical flux operation of microfiltration. J. Mem. Sci., 107 (1995) 165-171.

[9] Field, R.W., Wu, D., Howell, J.A. and Gupta, B.B., Critical flux concept for microfiltration fouling, J. Mem. Sci., 100 (1995) 259-272.

[10] Kwon, D.Y. and Vigneswaran, S., Influence of particle size and surface charge on critical flux of crossflow microfiltration. Wat. Sci. Tech., 38 (1998) 481 - 488.

[11] Ngo, H.H. and Vigneswaran, S., Application of floating medium filter in water and wastewater treatment with contact-flocculation filtration arrangement. Journal of Water Reserch - IAWQ, 29 (9) (1995) 2211-2213. 
Table 1 Characteristics of powdered activated carbon (PAC) used

\begin{tabular}{cc}
\hline Specification & PAC-WB \\
\hline Iodine number $(\mathrm{mg} / \mathrm{g} \mathrm{min})$ & 900 \\
Ash content $(\%)$ & $6 \mathrm{max}$. \\
Moisture content $(\%)$ & $5 \mathrm{max}$. \\
Bulk density $\left(\mathrm{kg} / \mathrm{m}^{3}\right)$ & $290-390$ \\
Surface area $\left(\mathrm{m}^{2} / \mathrm{g}\right)$ & 882 \\
Nominal size & (0) $\min$ finer than 75 micron \\
Type & Wood based \\
Mean pore diameter $(\AA)$ & 30.61 \\
Micropore volumn $(\mathrm{cc} / \mathrm{g})$ & 0.34 \\
Mean diameter $(\mu \mathrm{m})$ & 19.71 \\
Product code & MD3545WB powder \\
\hline
\end{tabular}


Table 2 Specific characteristics of wastewater used over the experimental period

\begin{tabular}{cc}
\hline Wastewater character & Range \\
\hline Total Organic Carbon (TOC) & $1.6-3.8 \mathrm{mg} / \mathrm{L}$ \\
Turbidity & $0.8-6 \mathrm{NTU}$ \\
Orthophosphate $\left(\mathrm{PO}_{4}^{-3}\right)$ & $0.5-12 \mathrm{mg} / \mathrm{L}$ \\
Suspended Solid (SS) & $2-15 \mathrm{mg} / \mathrm{L}$ \\
\hline
\end{tabular}


Table 3 The critical flux under different pretreatment conditions

\begin{tabular}{lc}
\hline \multicolumn{1}{c}{ Experimental condition } & Critical flux $\left(\mathbf{L}^{2} \mathbf{m}^{2} \mathbf{h}\right)$ \\
\hline Secondary wastewater & 150 \\
Wastewater after flocculation $\left(\mathrm{FeCl}_{3}: 50 \mathrm{mg} / \mathrm{L}\right)$ & 200 \\
Wastewater after adsorption $(\mathrm{PAC}: 2 \mathrm{~g} / \mathrm{L})$ & 900 \\
Wastewater after flocculation $\left(\mathrm{FeCl}_{3}: 50 \mathrm{mg} / \mathrm{L}\right)$ & 1400 \\
and adsorption (PAC: $2 \mathrm{~g} / \mathrm{L})$ & \\
\hline
\end{tabular}


Table 4 Effluent quality with different pretreatment.

$\left(\right.$ FMF velocity $=40 \mathrm{~m} / \mathrm{h} ; \mathrm{FeCl}_{3}=50 \mathrm{mg} / \mathrm{L} ;$ PAC dose $=1 \mathrm{~g} / \mathrm{L} ;$ PAC mixing time $1-2$ minutes; Influent TOC average $=2.75 \mathrm{mg} / \mathrm{L}$; Experimental duration $=2$ hours)

\begin{tabular}{|c|c|c|c|c|c|c|}
\hline $\begin{array}{c}\text { Quality of } \\
\text { biologically } \\
\text { treated } \\
\text { effluent }\end{array}$ & $\begin{array}{c}\text { Membrane } \\
\text { without } \\
\text { pretreatment }\end{array}$ & $\begin{array}{c}\text { Removal } \\
\text { efficiency } \\
(\%)\end{array}$ & $\begin{array}{c}\text { Flocculation } \\
\text { + Membrane }\end{array}$ & $\begin{array}{c}\text { Removal } \\
\text { efficiency } \\
(\%)\end{array}$ & $\begin{array}{c}\text { Flocculation } \\
\text { +adsorption } \\
\text { + membrane }\end{array}$ & $\begin{array}{c}\text { Removal } \\
\text { efficiency } \\
(\%)\end{array}$ \\
\hline TOC (mg/L) & 2.53 & 20 & 1.71 & 33 & 0.07 & 99.7 \\
\hline $\mathrm{PO}_{4}^{-3}(\mathrm{mg} / \mathrm{L})$ & 6.3 & 5 & 0.24 & 94 & 0.2 & 94 \\
\hline $\begin{array}{c}\text { Turbidity } \\
(\mathrm{NTU})\end{array}$ & $<0.1$ & - & $<0.1$ & - & $<0.1$ & - \\
\hline $\begin{array}{c}\text { Flux Decline } \\
\left(\mathrm{L} / \mathrm{m}^{2} . \mathrm{h}\right)\end{array}$ & 277 to 245 & - & 277 to 265 & - & 277 to 245 & - \\
\hline
\end{tabular}




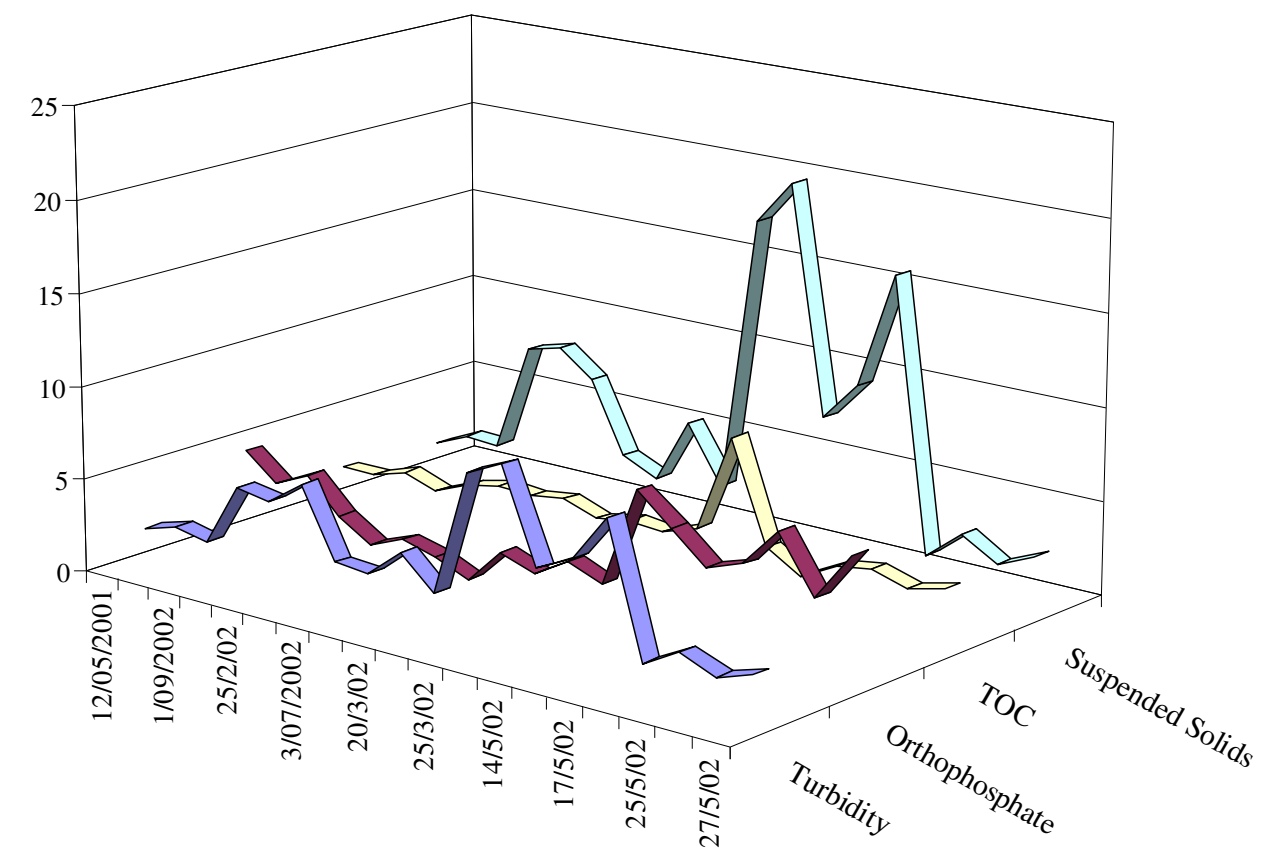

Figure 1. Influent variation over time (Turbidity (NTU); Orthophosphate $\left(\mathrm{PO}_{4}^{-3} \mathrm{mg} / \mathrm{L}\right.$ ); TOC (ppm C); Suspended Solids (mg/ L). 


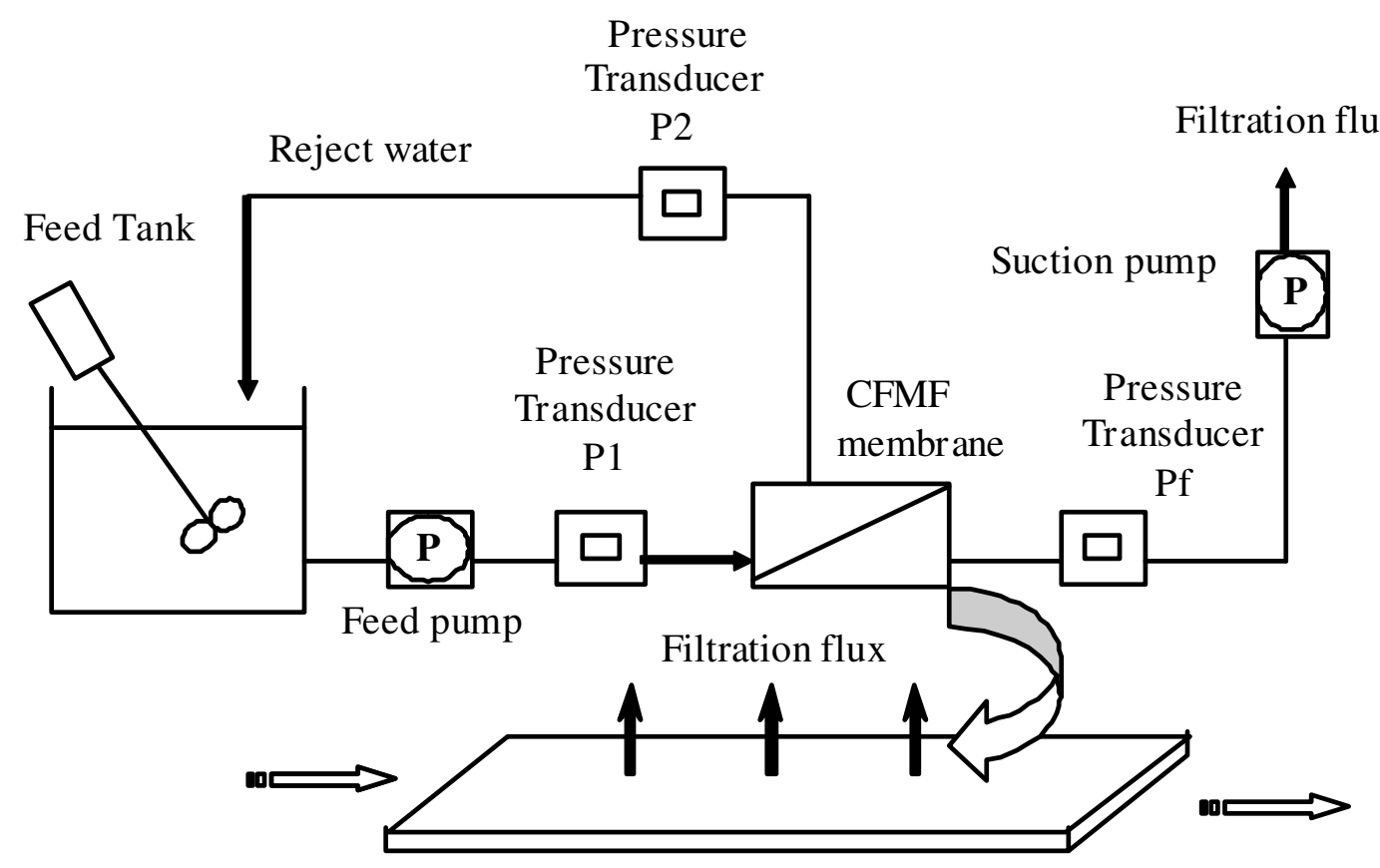

Figure 2 The schematic diagram of the CFMF experimental set-up 


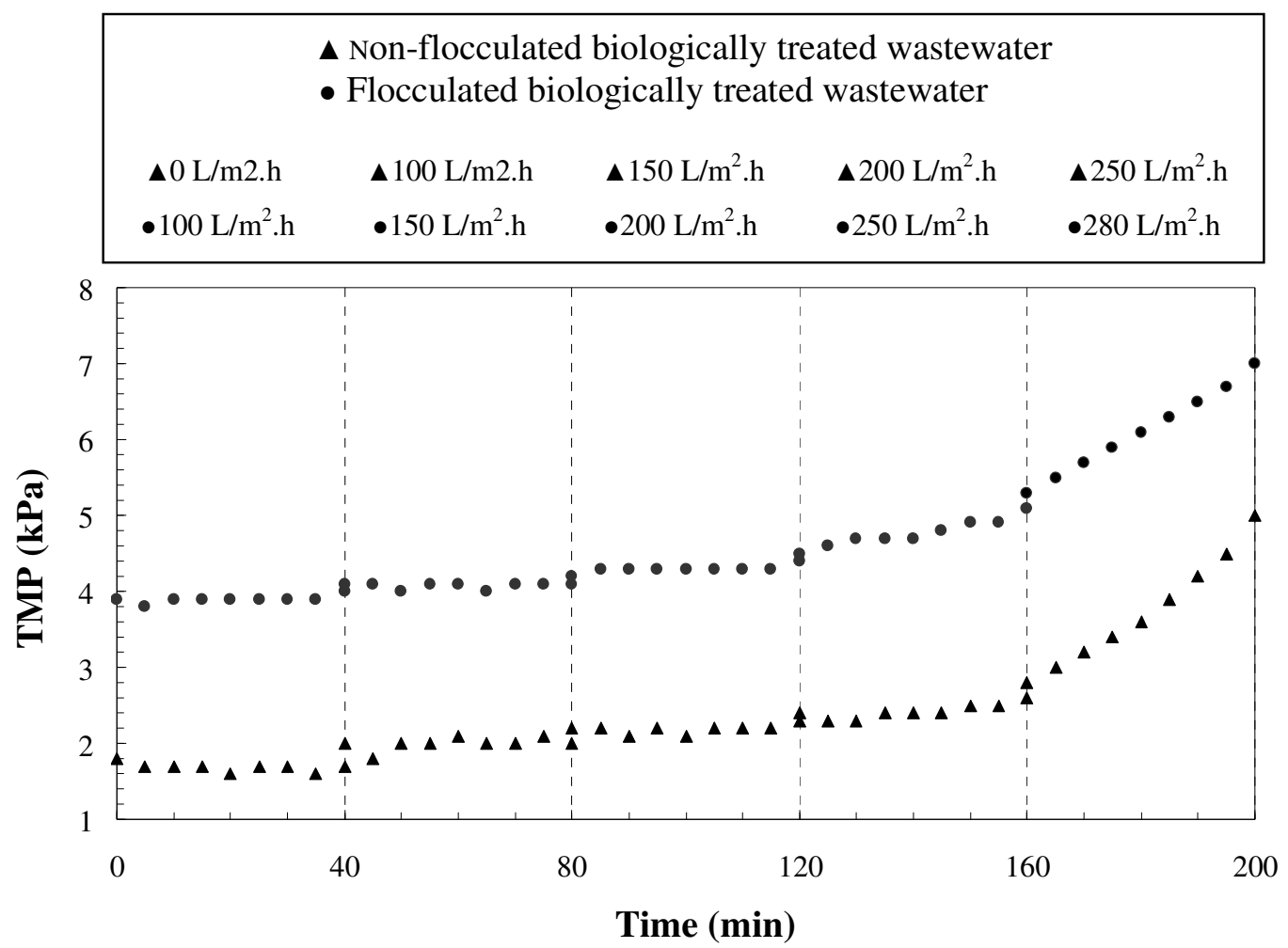

Figure3 Effect of flocculation on critical flux

$\left(\mathrm{FeCl}_{3}=50 \mathrm{mg} / \mathrm{L} ;\right.$ crossflow velocity $=1 \mathrm{~m} / \mathrm{s} ;$ membrane pore size $\left.=0.65 \mu \mathrm{m}\right)$

(Note: The ranges of filtration flux values for flocculated and non-flocculated wastewater are different) 


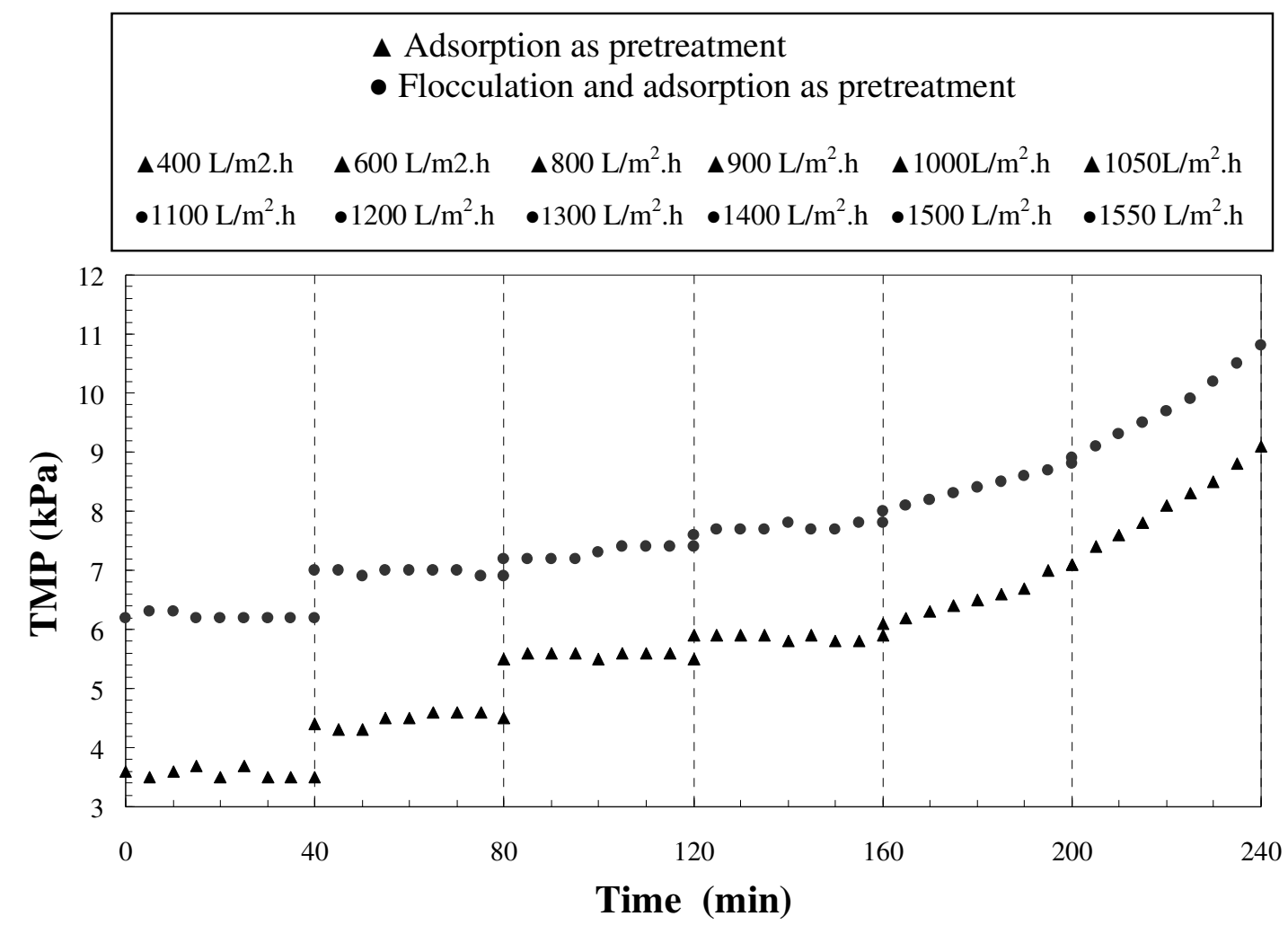

Figure 4 Effect of (i) adsorption and (ii) flocculation and adsorption as pretreatment on critical flux $\left(\mathrm{PAC}=2 \mathrm{~g} / \mathrm{L} ; \mathrm{FeCl}_{3}=50 \mathrm{mg} / \mathrm{L} ;\right.$ crossflow velocity $=1 \mathrm{~m} / \mathrm{s}$; membrane pore size $=0.65 \mu \mathrm{m}$ )

(Note: The ranges of filtration flux values for adsorption and flocculation-adsorption pretreatment are different) 


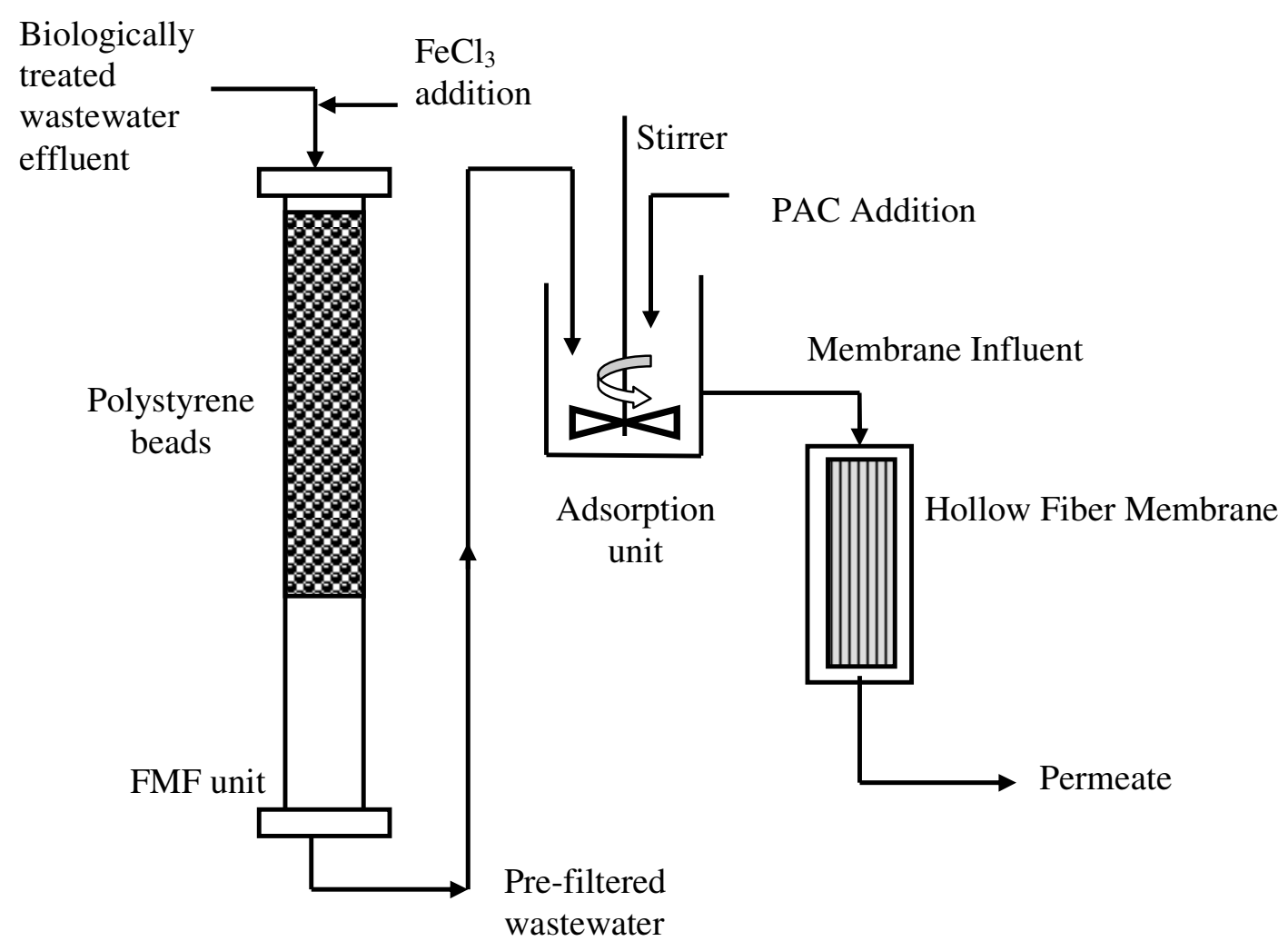

Figure 5 Schematic of flocculation-adsorption-microfiltration hybrid system 
(a) Phosphorus profile

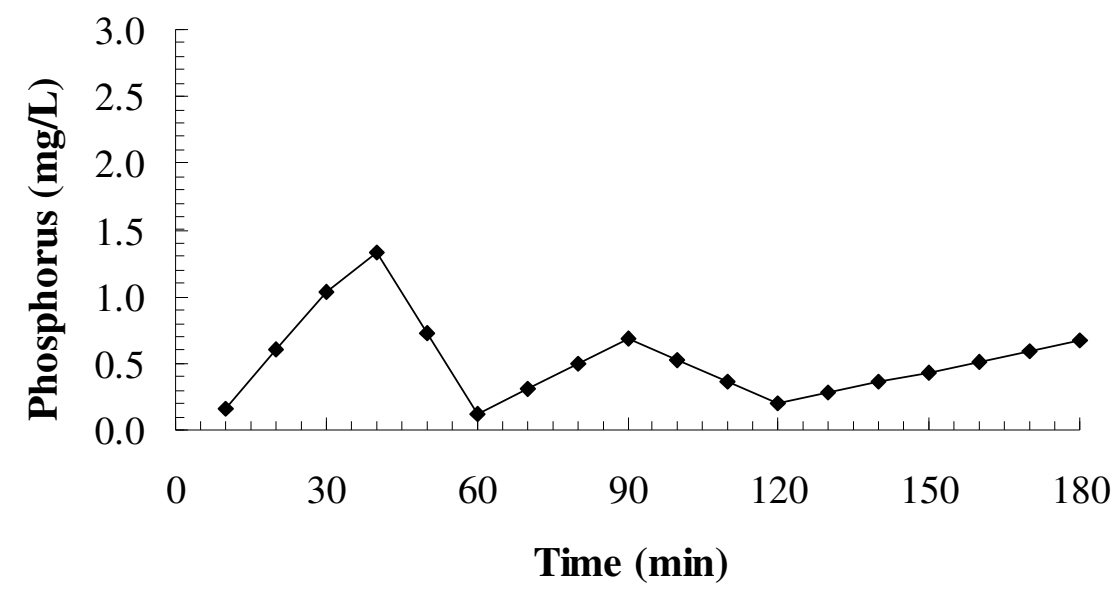

(b) TOC profile

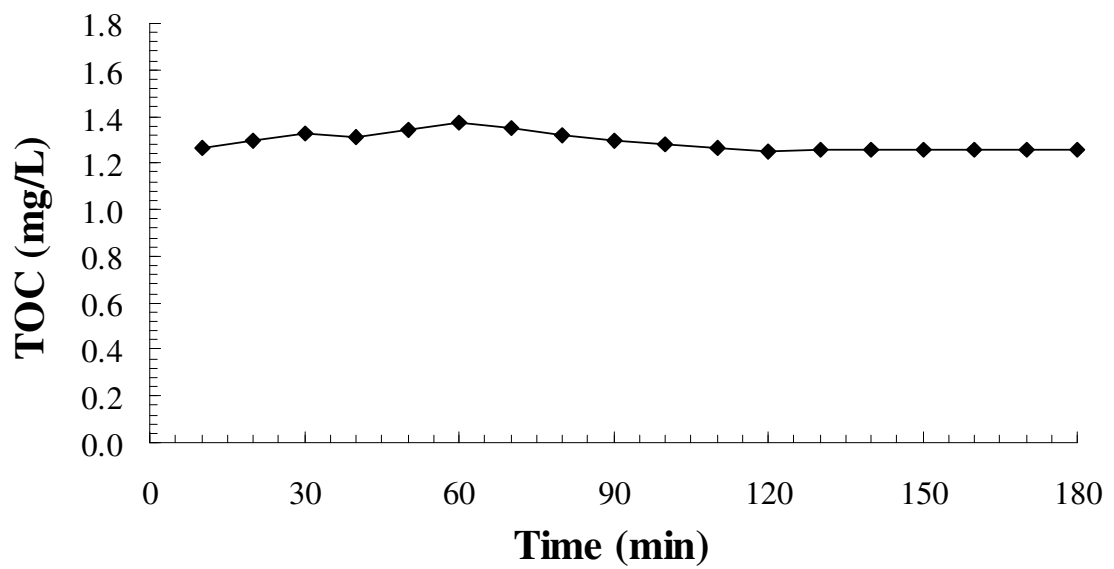

(c) Headloss profile

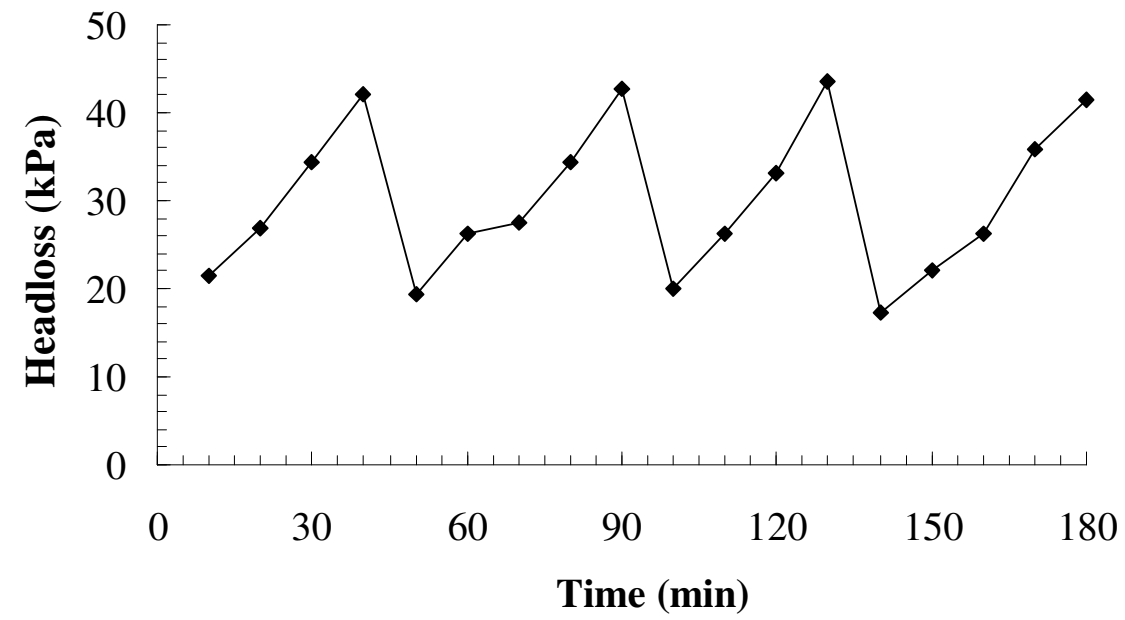

Figure 6 The floating medium flocculator performance

(filter velocity $=30 \mathrm{~m} / \mathrm{h}$; polystyrene medium diameter $=1.9 \mathrm{~mm}$; filter depth $=0.8 \mathrm{~m}$; density $=50 \mathrm{~kg} / \mathrm{m}^{2}$; flocculator backwash frequency $=45 \mathrm{~min}$; backwash duration $=1$ min; influent $\mathrm{TOC}=2.09 \mathrm{mg} / \mathrm{L}$; orthophosphate $=2.68 \mathrm{mg} / \mathrm{L}$ ) 


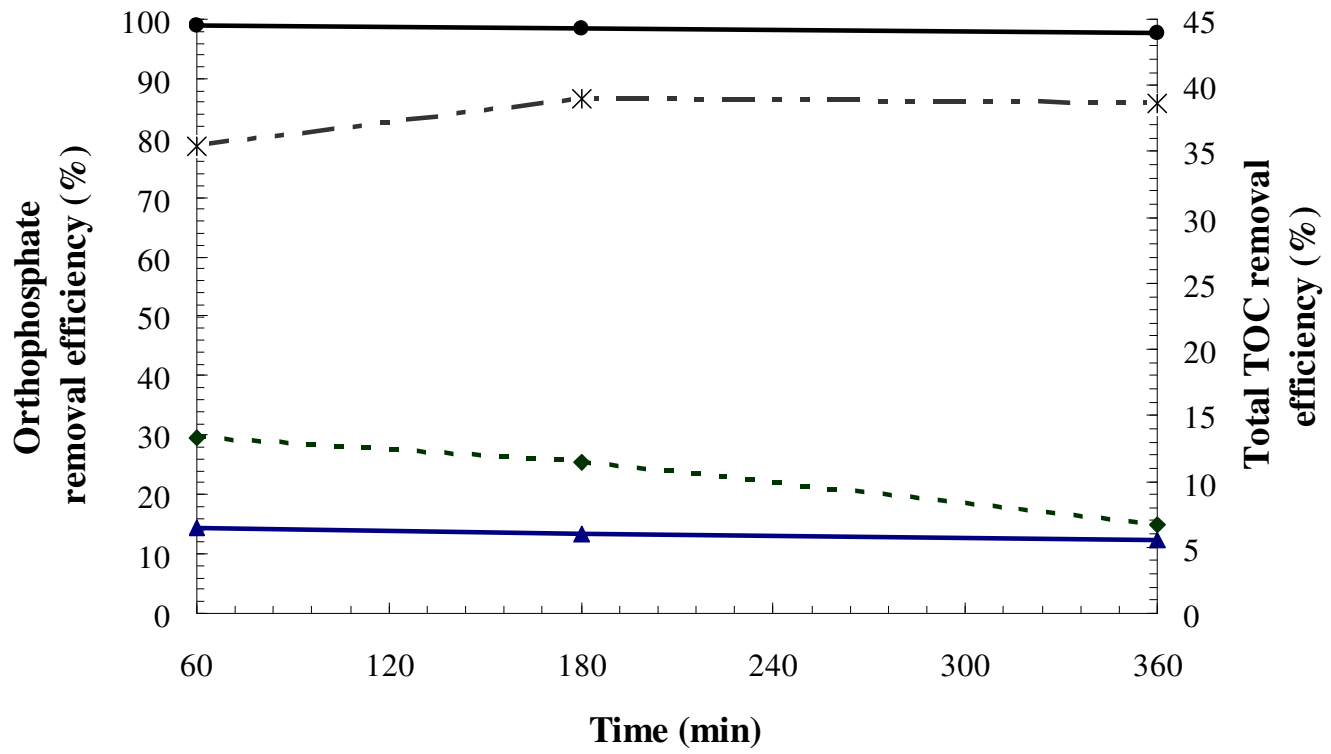

$\Delta$ Orthophosphate profile without flocculation

- Orthophosphate profile with flocculation

- TOC profile without flocculation

* TOC profile with flocculation

Figure 7 Removal efficiency comparisons with and without flocculation as pretreatment (Filtration flux: $220 \mathrm{~L} / \mathrm{m}^{2} . \mathrm{h}$; membrane backwash frequency $=36 \mathrm{~min}$ (backwash duration $2 \mathrm{~min}$ ); $\mathrm{FMF}$ velocity $=30 \mathrm{~m} / \mathrm{h} ; \mathrm{FeCl}_{3}$ dose $=50 \mathrm{mg} / \mathrm{L}$; flocculator backwash frequency $=60 \mathrm{~min}$ (backwash duration $1 \mathrm{~min})$ ) 


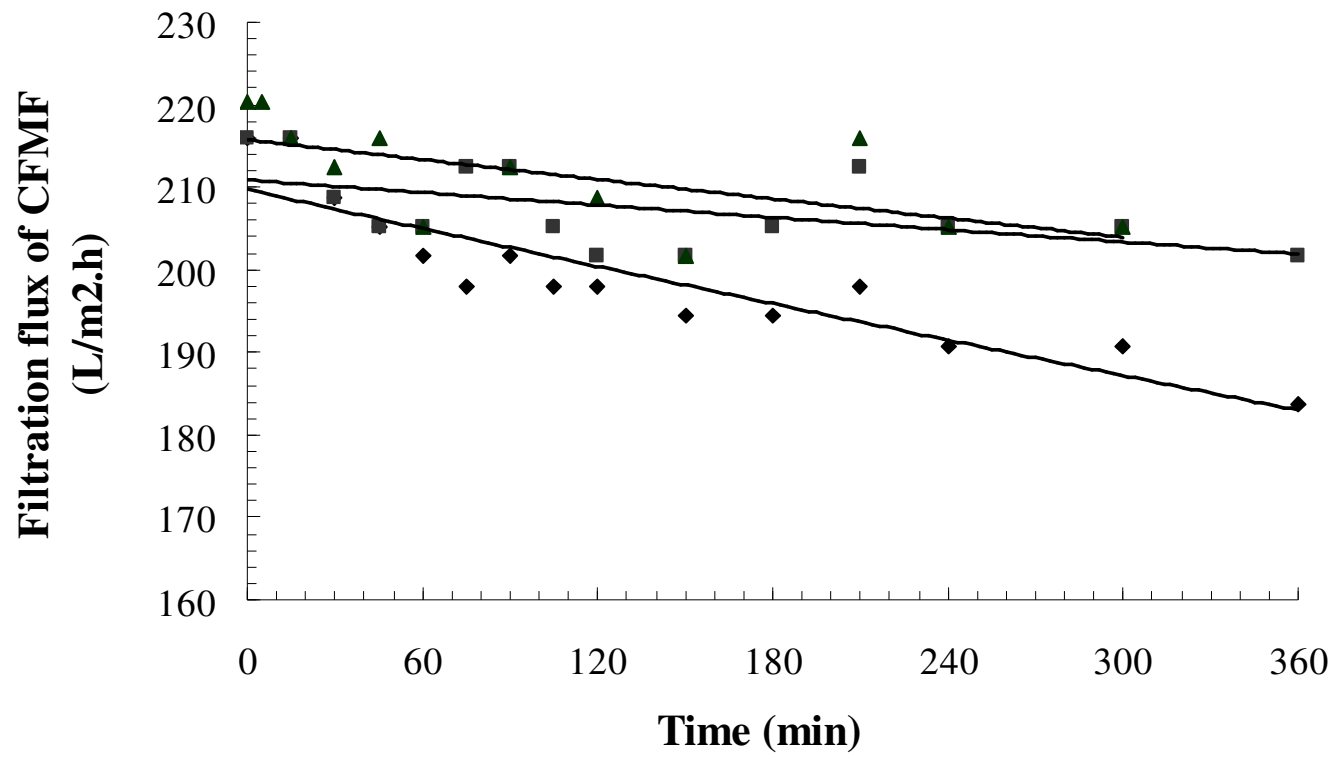

- CFMF alone

- With flocculation as pretreatment

$\Delta$ With flocculation and adsorption as pretreatment

Figure 8 Variation of filtration flux of CFMF with filtration time for different pretreatment (Filtration flux $=220 \mathrm{~L} / \mathrm{m}^{2} . \mathrm{h}$; membrane backwash frequency $=36 \mathrm{~min}$; filtration velocity $=30 \mathrm{~m} / \mathrm{h} ; \mathrm{PAC}=1 \mathrm{~g} / \mathrm{L} ; \mathrm{FeCl}_{3}=50 \mathrm{mg} / \mathrm{L}$; flocculator backwash frequency $=60 \mathrm{~min}$ ) 


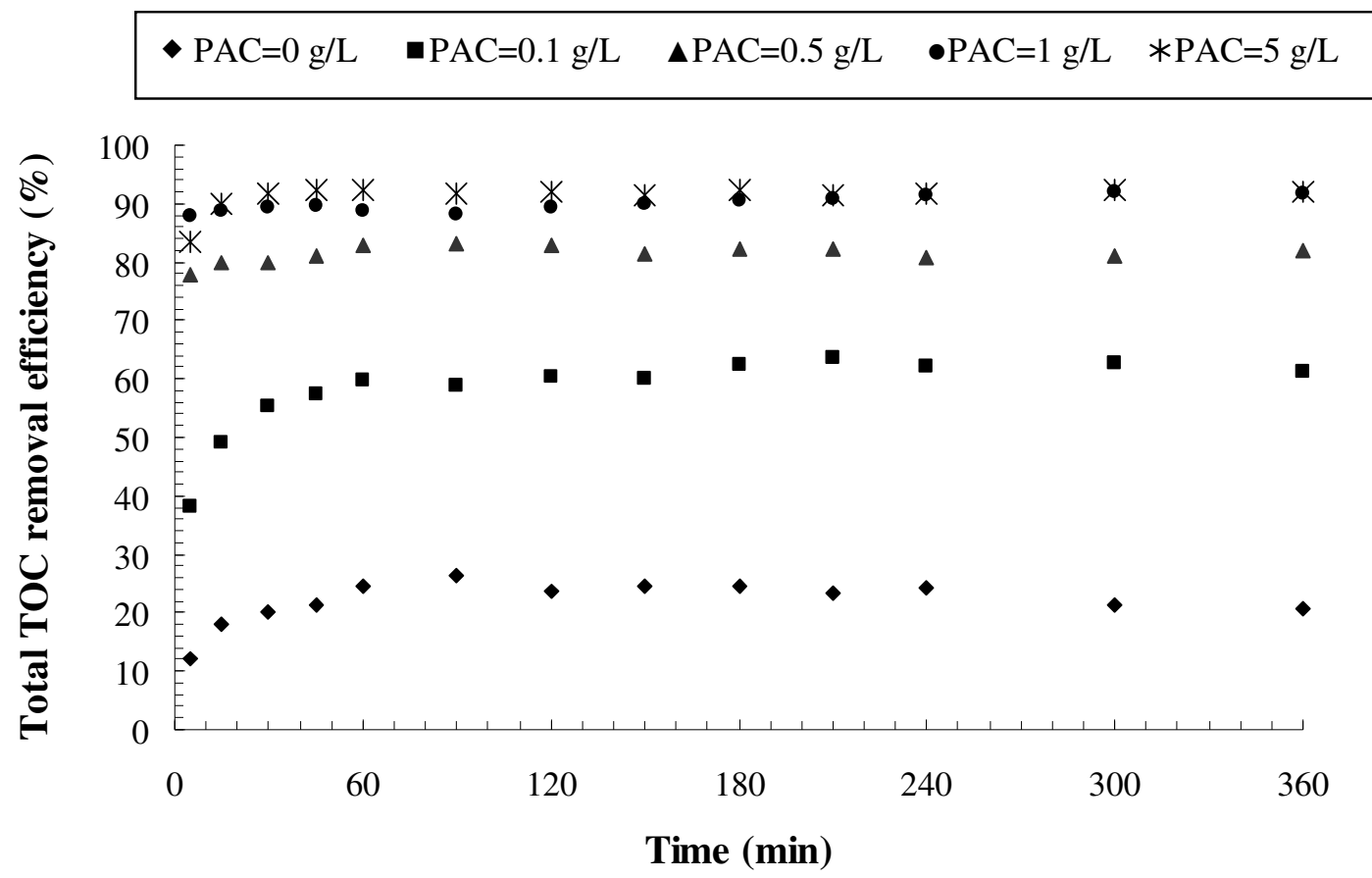

Figure 9 Filtration flux of adsorption-microfiltration hybrid system. (Influent TOC $=2.4-3 \mathrm{mg} / \mathrm{L}$; membrane backwash frequency $=36 \mathrm{~min}$; backwash duration $=2$ min; PAC mixing speed: $125 \mathrm{rpm}$ ) 


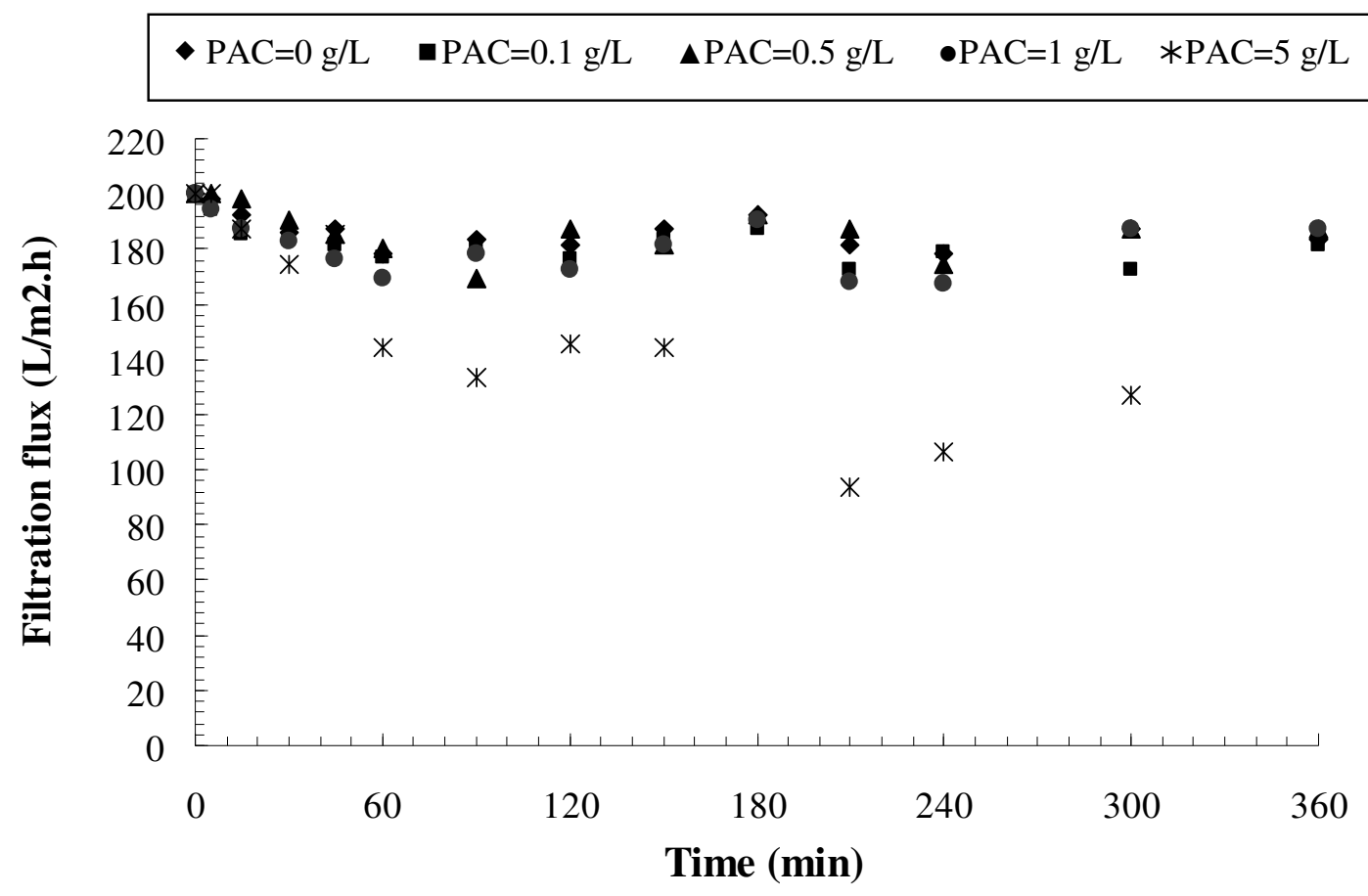

Figure 10 TOC removal efficiency of adsorption-microfiltration system (Influent TOC $=2.4-3 \mathrm{mg} / \mathrm{L}$; membrane backwash frequency $=36$ min (backwash duration $=2 \mathrm{~min}$ ); PAC mixing speed: $125 \mathrm{rpm}$ ) 


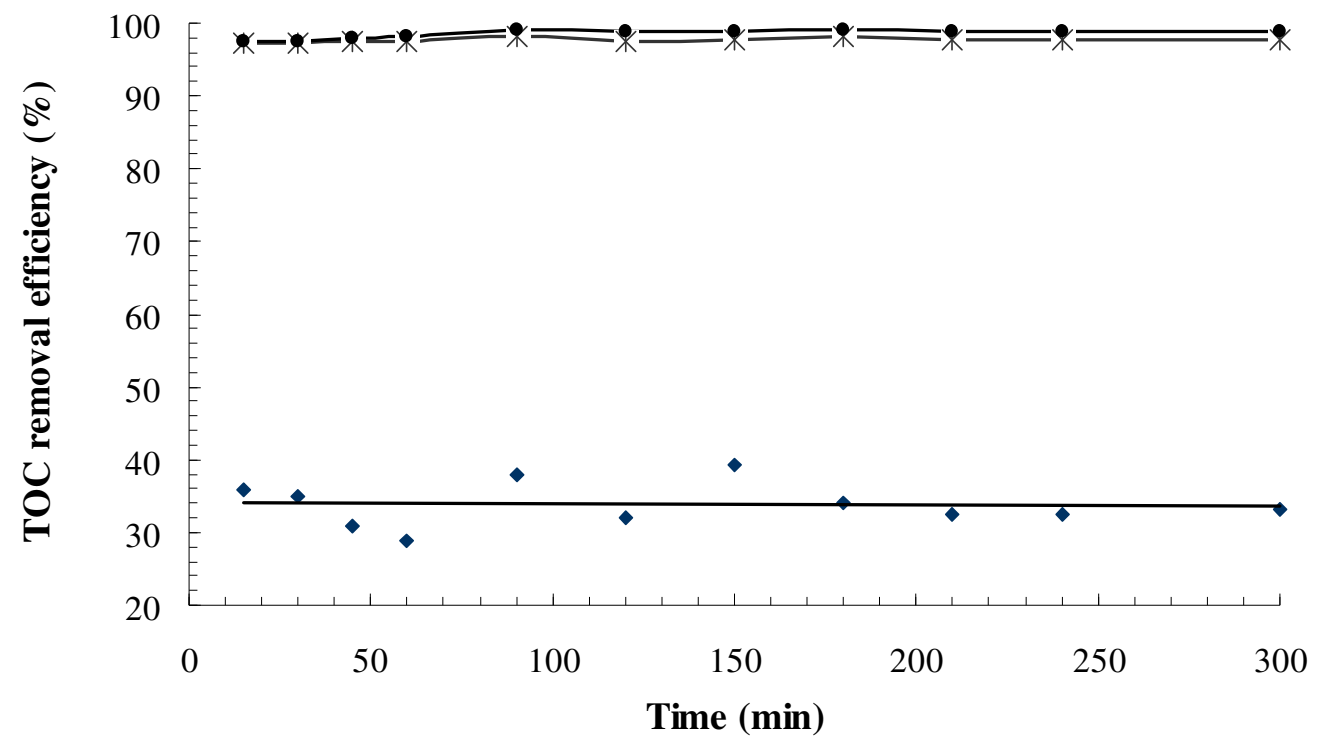

- After flocculation

* After flocculation and adsorption

\ After flocculation, adsorption and membrane

Figure 11 TOC removal at different stages of the flocculation-adsorptionmicrofiltration hybrid system (Filtration flux $=220 \mathrm{~L} / \mathrm{m}^{2} . \mathrm{h}$; membrane backwash frequency $=36 \mathrm{~min}$ (backwash duration $=2 \mathrm{~min}$ ); FMF filtration velocity $=30 \mathrm{~m} / \mathrm{h}$; $\mathrm{PAC}=1 \mathrm{~g} / \mathrm{L} ; \mathrm{FeCl}_{3}=50 \mathrm{mg} / \mathrm{L}$; flocculator backwash frequency $=60 \mathrm{~min}$ (backwash duration $=1 \mathrm{~min})$ ) 